\title{
Amphibians breeding in refuge habitats have larvae with stronger anti-predatory responses
}

\author{
Raoul Manenti ${ }^{a, *}$, Andrea Melotto ${ }^{\text {a }}$, Mathieu Denoël ${ }^{b}$, Gentile Francesco Ficetola ${ }^{c, d}$ \\ ${ }^{a}$ Dipartimento di Bioscienze, Università degli Studi di Milano, Milano Italy \\ ${ }^{b}$ Laboratory of Fish and Amphibian Ethology, Behavioural Biology Unit, Freshwater and Oceanic \\ Science Unit of Research (FOCUS), University of Liege, Liege, Belgium \\ ${ }^{c}$ Université Grenoble-Alpes, Laboratoire d'Ecologie Alpine (LECA), Grenoble, France \\ ${ }^{d}$ Centre National de la Recherche Scientifique, Laboratoire d'Ecologie Alpine (LECA), Grenoble, \\ France
}

*Correspondence: R. Manenti, Dipartimento di Bioscienze, Università degli Studi di Milano, Via Celoria, 26, 20133 Milano, Italy

E-mail address: raoulmanenti@gmail.com

\begin{abstract}
Anti-predator responses are a key determinant of the successful persistence of prey, and behavioural modifications are a frequent anti-predator strategy. However, conspecific populations often inhabit heterogeneous environments. This can determine local adaptations, and might also induce variation in anti-predator responses. Nevertheless, there is limited information on whether heterogeneity of predation risk among populations determines variation in anti-predator response. Here we studied the fire salamander Salamandra salamandra, a species that can lay larvae both in epigeous streams and caves - habitats that are predator-rich and predator-free, respectively, and measured differences in antipredator responses across populations with different predation risk. We combined field surveys and laboratory experiments to understand the role of predation risk on the activity patterns of larvae, while measuring behavioural differences among populations. We reared larvae from different habitats in safe and risky conditions and tested their response to predator cues before and after rearing. In the field, predation risk was much higher in epigean streams than in caves; larvae moved more in the absence of predators and when the light intensity was low. During laboratory experiments, larvae were less active if reared in risky conditions, but cave larvae showed a stronger response to risk than stream larvae. Therefore, larvae from sites without predators showed higher anti-predator responses than those from risky habitats. This response fits the predictions of the risk allocation model, in which prey from habitats with high background level of risk need to be active even when predators are present, to satisfy their energetic demands. Our findings show that anti-predator behaviour may be strongly different among populations and stresses the importance of integrating this variability in studies on predatory responses.
\end{abstract}

Keywords: amphibians, background risk, behavioural avoidance, predation risk, risk allocation hypothesis, Salamandra salamandra 
Predators can affect prey through consumption, but also through non-consumptive effects that alter the morphology, life history and behaviour of prey (Davenport \& Chalcraft, 2013; Preisser \& Bolnick, 2008; Winandy \& Denoël, 2015), with major impacts on prey population dynamics (Davenport \& Chalcraft, 2013). For instance, semi-aquatic organisms with complex life cycles are able to assess the predation risk in a water body and modulate breeding activity by selecting habitats with fewer predators (Stav et al., 2000; Winandy et al., 2015). Several studies have assessed the nonconsumptive effects of predation risk by evaluating how anti-predator responses enhance fitness and by measuring the costs and the trade-offs of such responses, which are keystones to understanding several ecological and conservation aspects (Amo et al., 2003; Blanchet et al., 2007; Yorzinski et al., 2015). Such studies often use individuals of the same origin, without taking into account potential variations among populations (Blaustein, 1997; Hernandez \& Peckarsky, 2014; Kishida et al., 2009). However, local adaptations are common among populations that inhabit heterogeneous environments, thus spatial heterogeneity in predation pressure might induce variation in anti-predator responses.

The reduction in activity levels under high predation risk is common anti-predation behaviour (Kishida et al., 2009; Kishida et al., 2011). Movements increase the risk of being detected by predators, but are often necessary to find resources such as food or partners, leading to a trade-off between reducing mortality and acquiring resources (Carlson \& Langkilde, 2014). Some studies have underlined how individuals from populations living in risky habitats can display specific behavioural adaptations, which limit predation risk. In some cases, larvae of amphibians from habitats with high levels of predation risk (e.g., predatory fish) show a lower level of activity (e.g., movement decrease) and an even stronger reduction in activity rates in the presence of predators (Chivers et al., 2001; Storfer \& Sih, 1998). However, cases exist in which individuals from populations exposed to predators have higher activity levels, as this can improve their foraging and allow them to rapidly grow to a large size, thus reducing the period during which individuals suffer predation risk (Urban, 2007). In practice, anti-predator adaptations can be highly variable, suggesting that knowledge concerning how the heterogeneity of predation risk among populations and habitats determines the variation in anti-predator response among populations is incomplete.

Predation risk is variable over space and time, and this variability is crucial in determining how prey respond to risk (Ferrari, 2014). As a consequence, the background level of risk is an additional factor potentially affecting the outcome of prey responses, as it can influence the readiness of a species to respond to predators (Ferrari, 2014; Ferrari et al., 2015). For instance, prey inhabiting habitats with high level of risk can decrease their vigilance and be particularly active during brief periods of safety (paradox of risk-allocation hypothesis: Ferrari et al., 2009; Lima \& Bednekoff, 1999). Furthermore, the background level of risk can strongly modify the overall activity level of prey, and this influences the outcome of their interactions with predators, with increase or decrease of survival depending on the predator type (Ferrari et al., 2015).

The fire salamander, Salamandra salamandra, is a usually epigeous taxon that breeds in streams, but some populations have also colonised subterranean environments in which larvae successfully complete their development (Manenti et al., 2013a). On one hand, subterranean environments can provide advantages, such as more stable environmental conditions and limited predation risk. On the other hand, salamanders in these habitats face major challenges, such as food scarcity (Manenti et al., 2015). Evidence suggests that local adaptations to underground environments are present, with cave populations also showing a higher behavioural plasticity than epigeous stream populations. Such plasticity allows them to modulate activity levels in function of behavioural conditions and availability of prey, thus helping the colonisation of such challenging habitat (Manenti et al., 2013a; Manenti \& Ficetola, 2013).

In this study, we combined field surveys and laboratory experiments to assess whether antipredator responses of salamander larvae differ among populations facing different levels of predation risk. Firstly, we evaluated in the field whether movement is reduced in habitats with a higher predation risk. Secondly, we reared larvae from populations with a different level of predation risk (caves: absence of aquatic predators for salamander larvae; streams: presence of 
predators), and tested $i$ ) whether being reared under risky conditions or in the presence of predatory cues determines a reduction in movement; $i$ ) whether the response to risky conditions is similar or differs among populations that experience different predation risks.

\section{METHODS}

\section{Field surveys}

We studied fire salamander populations from Lombardy (NW Italy; approximately $45^{\circ} 48^{\prime} \mathrm{N}$, $\left.9^{\circ} 02^{\prime} \mathrm{E}\right)$. In this area, the fire salamander is ovoviviparous and usually produces larvae in streams, but caves are also often used by salamanders for giving birth to larvae (Fig. S1). All these salamander larvae are fully aquatic and have external pairs of gills. Adult females actively enter caves and select them as breeding sites; no larvae in the chosen sites could have drifted into these environment from superficial waters, because all sites are springs that receive water exclusively from the subterranean aquifer (Manenti \& Ficetola, 2013; Manenti et al., 2009). In these underground habitats, salamander larvae successfully grow and metamorphose (Manenti et al., 2011).

We surveyed 52 sites (15 cave pools and 37 outdoor springs and stream pools; Fig. S1) between February 2014 and June 2015 during the night and day. We performed two visits for each site, the same observer performed all the surveys. On all the sampling occasions, we recorded the number of active salamander larvae, i.e., the number of larvae visible from the pool border in 5-min visual surveys. To this purpose, we approached the pools without lightening it and once at the border of the pool, we lightened it with a torch (Petzl Ultra Vario) and directly counted the larvae. Subsequently, we estimated the total number of larvae using two successive removal samplings with a fine mesh net and applying the removal method (Chao \& Chang, 1999). Larvae were released at their place of capture immediately after the census. We then calculated the frequency of active larvae as a proportion of the total number of larvae. As environmental variables, we recorded the maximum light intensity (illuminance) on the pool surface using a CEM DT8820 lux-metre (CEM-instruments, Shenzhen, China), and estimated the biomass of predators (dragonfly larvae; $\mathrm{g} / \mathrm{m}^{2}$ ) through pipe sampling (diameter: $25 \mathrm{~cm}$ ) (Dodd, 2010); see Limongi et al., (2015) for additional details on invertebrate samplings. All the studied pools were devoid of fish and we excluded from the analyses very few epigean sites $(n=5)$ in which we found native crayfish.

\section{Laboratory experiments}

We performed behavioural experiments to assess the variation in movement among salamander larvae born under different risk conditions in underground and epigeous streams. We collected larvae at developmental stage 1 (newborns: well-developed tail-fin and the tip of the fin bluntly rounded (Jusczcyk \& Zakrzewski, 1981) from underground pools (67 individuals from six sites) and neighbouring epigeous pools or slow-running water streams (96 individuals from eight sites). Larvae were individually maintained at a mean temperature of $18^{\circ} \mathrm{C}$, exposed at natural photoperiod, in $10 \times 11 \mathrm{~cm}$ perforated (diameter of perforations: $2 \mathrm{~mm}$ ) transparent plastic containers placed in six independent water-filled blocks (i.e., plastic containers of 40 x $50 \mathrm{~cm}$, water depth: 5 $\mathrm{cm}$ ). Larvae were randomly assigned to three rearing treatments, with two blocks per treatment (each one containing 12 larvae). The rearing treatments were: control (absence of dragonfly larvae), predator without contact ('no contact') and predator with contact ('contact'). Under the predator without contact treatment, two dragonfly larvae (Cordulegaster bidentata) were free to move within the block. Salamanders could receive dragonfly cues through the perforated walls of their container, but were protected from predation or direct contact. In the predator with contact condition, a dragonfly larva was placed in the container of the larva with predation prohibited, twice-weekly, for $30 \mathrm{~s}$. All C. bidentata larvae used were at the pre-metamorphosis stages (mean length $\pm \mathrm{SE}=31.8 \pm 0.4 \mathrm{~mm}$ ) and are major predators of salamander larvae within the study area (Manenti et al., 2013b). 
Salamandra salamandra larvae were fed ad libitum every 2 days with Chironomus sp. larvae. Chironomids were provided also ad libitum to C. bidentata larvae for a total of 8-10 prey per week. Salamander larvae were kept without food for three days before performing behavioural tests to get the same level satiety. This absence of feeding does not affect salamander success and naturally occurs in the wild (Limongi et al., 2015). The body size (total length) did not differ between salamander larvae in the caves or streams, or between rearing conditions (at the beginning and at the end of the experiment, $t$-tests showed for all $P>0.2$ ).

During behavioural tests, we assessed the effect of the presence of predator cues on salamander movements. These tests allowed us also to determine the effect of the site of origin (epigean versus hypogean streams) and rearing conditions (predator and predator-free environments). Predator cues were obtained by maintaining six C. bidentata larvae for $24 \mathrm{~h}$ in $1.5 \mathrm{~L}$ of dechlorinated tap water; the water was aliquoted $(1 \mathrm{~mL})$ and immediately stored at $-20^{\circ} \mathrm{C}$ until use for behavioural tests, following the procedure of Epp \& Gabor (2008). As control cues, we used $1 \mathrm{~mL}$ tap water. Behavioural tests started 3 days after salamander collection, and were repeated after 45 days of rearing; the identity of the larvae to be tested in each trial and the treatment order were randomly selected, until each larva was tested twice with the predator and twice with control cues. Both tests were repeated 3 days after salamander collection and at 45 days of rearing. During the behavioural tests, each larva was individually placed in a $13.5 \times 18.3 \mathrm{~cm}$ plastic container filled with $5 \mathrm{~cm}$ water under daylight condition with an average lux intensity of 500 lux and was allowed to acclimatise for $3 \mathrm{~min}$. At the beginning of the test, $1 \mathrm{~mL}$ water with the test cues was cautiously placed with a pipette on the opposite side of the arena by the same person. The trials lasted for $7 \mathrm{~min}$. The entire observation tank was video-recorded (Panasonic SDR-S7, Bracknell, UK) from above during all the trials.

We then used the Noldus Ethovision XT10 video-tracking software (Noldus Information Technology, Wageningen, The Netherlands) to measure the distance moved by the individuals during each trial. This software automatically detects salamander larvae on the basis of their contrast with the background and gives them a position over time ( 25 images/second over $7 \mathrm{~min} /$ trial in our setting) (Delcourt et al., 2013). By using this automatised method, it was possible to obtain the accurate locations of salamander larvae across time without any observer effect (Delcourt et al., 2013). As a behavioural parameter, we considered the total distance moved by the larva, since it represents a valuable indicator of the activity rate of amphibian larvae (Denoël et al., 2010; Uiblein et al., 1992; Uiblein et al., 1995) and strongly influences feeding performance, as larvae that move greater distances have better feeding success (Manenti et al., 2013a).

\section{Statistical analyses}

We used a linear mixed model (LMM) to assess whether the activity of larvae in the field was related to predation risk. The frequency of active larvae (arcsine square root transformed) was the dependent variable. As an independent variable, we used the log-transformed biomass of predators. We included the log-transformed incidence of light (activity levels are strongly affected by light conditions (Manenti et al., 2013a)) and habitat typology (cave/stream) as additional covariates. Site identity was included as a random factor. We used marginal and conditional $R^{2}\left(R^{2}{ }_{\mathrm{m}}\right.$ and $R^{2}$, respectively) to assess the fit of the LMM. The $R^{2}$ m represents the pure effect of fixed factors, whereas $R^{2}$ is the variance explained by the entire model (Nakagawa \& Schielzeth, 2013).

We used LMM to assess the factors that determined the behavioural responses of larvae in laboratory experiments to test and rearing conditions. The total distance moved (log-transformed) was the dependent variable. We considered four fixed independent factors: the origin of the larvae (cave/stream); the rearing conditions (control, no contact, contact), the presence of predator cues during the behavioural tests and the time of the test (the beginning of the experiment versus after 45 days). The origin was intended to test for differences among possible ecotypes; rearing conditions were intended to test for the influence of growing in different types of risky habitats and the test conditions were assumed to test for the immediate response to risk cues. We also tested two-way 
interactions. The final model included all the fixed factors and all the significant interactions. We used orthogonal contrasts to evaluate the significance of differences among the three rearing conditions (controls versus with predators; no contact versus contact). All our models included larva identity, site of origin and rearing block as random factors. Among random factors, rearing block explained a very small amount of variation, as removing block from the model slightly decreased AIC values (complete model: 1645.8; model without block: $\mathrm{AIC}=1644.7$ ). We present the results taking into account rearing block, but results remain identical if this factor was not included into analyses.

The sample size was not homogeneous among populations; therefore, in mixed models, the degrees of freedom were approximated (Satterthwaite, 1946). Analyses were performed using the lme4 and lmerTest packages in R (Bates et al., 2014; Kuznetsova et al., 2015).

\section{Ethical note}

The study was approved by the ethical committee of the Lombardy Region Authority and was authorised as complying with the regional law 10/2008, p.n.: F1.2013.0002091. The survival rate of larvae was $70.4 \%$, being much higher than that the values observed in natural populations (Limongi et al., 2015). All the larvae were released at their site of origin at the end of the study, following the recommendations of the permit. All individuals were daily checked and fed every two days. The aim of this study was to evaluate only the non-consumptive effects of dragonfly larvae on salamander larvae by observing their behaviour. Consequently, care was taken to plan the experiment accordingly and, thus, to avoid any larvae being harmed. To this end, dragonfly larvae were placed for only 30 sec in the tank of salamanders, thus preventing any predation act. This design was needed because one of the aims of the study was to compare indirect and direct contact with dragonfly larvae (see also Winandy \& Denoël, 2013b, 2015).

\section{RESULTS}

The mean abundance of predators in streams was $1.06 \mathrm{~g} / \mathrm{m}^{2}(\mathrm{SE}=0.48$; mainly dragonflies of the genus Cordulegaster), whereas we never captured dragonfly larvae in caves. The only other aquatic potential predator recorded was the native freshwater crayfish, Austropotamobius italicus, which was found in 5 additional epigean sites that were excluded from the analyses. Overall, a model including light, abundance of predators and site typology explained the variation in the activity level in natural conditions very well $\left(R_{\mathrm{m}}^{2}=0.60 ; R_{\mathrm{c}}^{2}=0.67\right)$. The proportion of active larvae decreased at high light levels $\left(F_{1,50.9}=113.6, P<0.001\right)$ and in sites with more predators $\left(F_{1,51.5}=7.6, P=0.008\right)$. When taking into account the effect of light and predator abundance, the frequency of active larvae was not different between caves and streams $\left(F_{1,55.6}=0.1, P=0.753\right)$ (Fig. 1).

In laboratory trials, the total distance moved ranged between 0 and $431.93 \mathrm{~cm}(\mathrm{mean}=47.81$, $\mathrm{SD}=61.15$ ). The total distance moved decreased after 45 days of rearing (Table 1$)$. The decrease was stronger in larvae reared under risky conditions than in controls (orthogonal contrast: $F_{1,826.8}=7.45$, $P=0.006$, Fig. 2a), whereas no difference was detected between rearing in contact with the predator and rearing with the predator but without contact $\left(F_{1,847.6}=2.34, P=0.126\right)$. Only larvae from caves showed a reduced activity in the presence of predator cues $\left(F_{1,706.7}=9.66, P<0.01\right.$; Fig. $\left.2 b\right)$. Furthermore, the activity of larvae from caves decreased with time more than that of larvae from streams $\left(F_{1,837.3}=4.33, P=0.03\right.$; Fig. $\left.2 \mathrm{c}\right)$. 

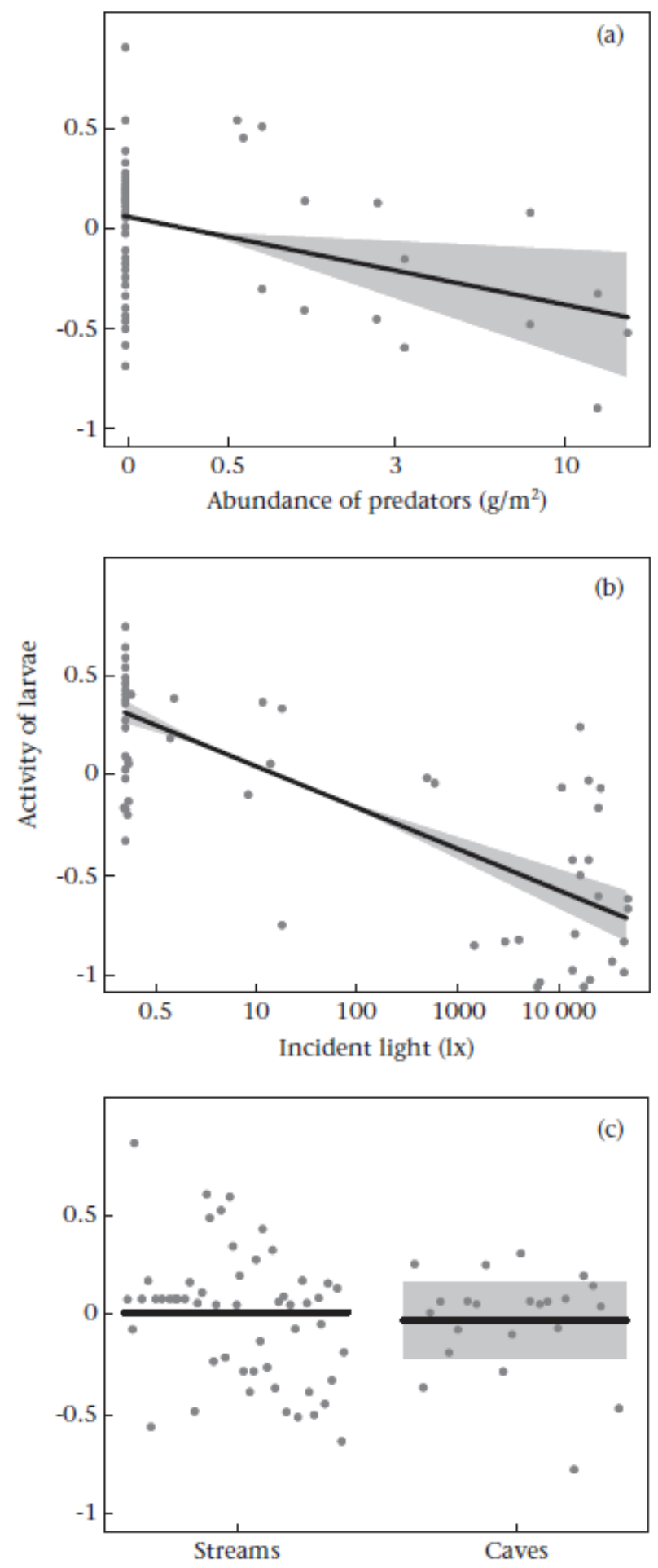

Figure 1. Contrast partial regression plots, showing the relationships between the proportion of active fire salamander larvae under natural conditions (arcsine square root transformed) and environmental variables $(\mathrm{a}=$ illuminance, $\mathrm{b}=$ predator abundance and $\mathrm{c}=$ site typology). Shaded areas represent the 95\% confidence bands. Plots were built using visreg 2.2 (Breheney \& Burchett, 2015). 

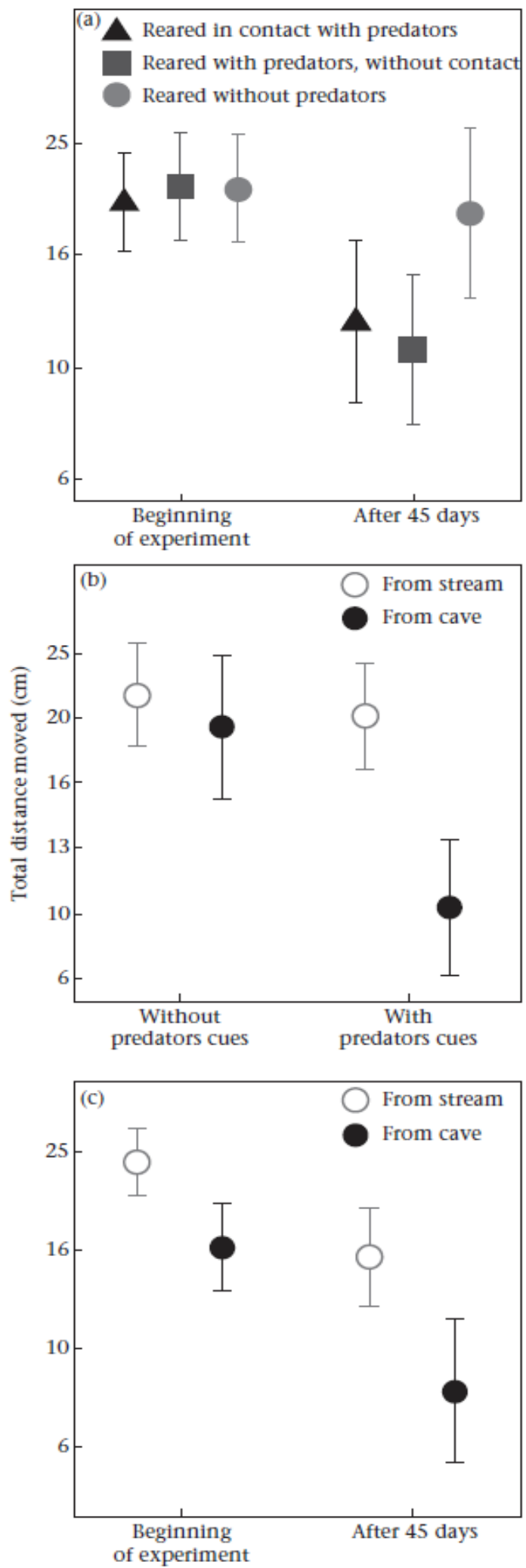

Figure 2. Effect of experimental conditions and origin on the activity (i.e., distance moved) of fire salamander larvae: analysis of experimental data. (a): effect of rearing conditions and time of the test; (b): effect of salamander origin and test conditions; (c): effect of time of the test and salamander origin. All the interactions shown in the plots are significant (see Table 1). Error bars are two standard errors of the mean. 
Table 1. Variables influencing the activity of fire salamander larvae.

Variables influencing the activity (i.e., total distance moved) of fire salamander larvae: results of mixed models assessing the effect of origin, rearing conditions and test conditions (with or without predator cues) on the movement of larvae. Only significant interactions are included in the model. The degrees of freedom are approximated following Satterthwaite (1946), thus, some are not integers.

\begin{tabular}{llll}
\hline Variable & $F$ & d.f. & $P$ \\
\hline Origin $($ cave/stream) & 0.17 & $1,14.8$ & 0.690 \\
Time of test & 16.36 & $1,831.0$ & $<0.001$ \\
Rearing conditions & 0.05 & $2,2.1$ & 0.950 \\
Test conditions & 0.43 & $1,708.2$ & 0.511 \\
Origin $\times$ test conditions & 9.66 & $1,706.7$ & 0.002 \\
Origin $\times$ time of test & 4.33 & $1,837.3$ & 0.038 \\
Rearing conditions $\times$ time of test & 4.99 & $2,836.8$ & 0.007 \\
\hline
\end{tabular}

\section{DISCUSSION}

The prediction of species interactions across heterogeneous habitats is a major challenge for zoologists and ecologists. Within a single species, adaptations change across neighbouring localities (Caspers et al., 2015; Krause \& Caspers, 2015), given that conspecific populations that exploit different habitats are subject to different selective pressures (Godsall et al., 2014). Longstanding ethological theory predicts that prey should show strong responses to threats, such as decreasing overall activity or escaping to reduce predation risk (Barnett \& Richardson, 2002; Carlson \& Langkilde, 2014; Lima, 1998). However, apparently opposite strategies, such as risky behaviours, might evolve in certain predator-rich habitats (Urban, 2007), and the risk allocation model has been proposed and developed to explain such contrasting strategies (Ferrari et al., 2015; Lima \& Bednekoff, 1999). The model predicts that, if predators are not always present, prey should show strong antipredator responses, while they are expected to increase their foraging effort and activity levels during low-risk situations. Conversely, living in risky conditions, in which predators are always present, can determine a limited antipredator surveillance, because prey may need to forage even when predators are present (Ferrari et al., 2009). Our study is in agreement with this model, as salamander larvae from populations breeding in the safer habitats (i.e., caves) showed a stronger antipredator behaviour (i.e., activity reduction) than those from populations in predator-rich habitats (i.e., epigean streams).

The combination of field and laboratory observations allowed us to obtain a complete picture of how anti-predator behaviour is modulated as a function of predation risk. In the field, light conditions and predation pressure both affected the movement patterns of fire salamander larvae: movements were more limited in the presence of predators and in the presence of light, i.e., when there is more risk of being detected by predators. In caves, darkness is constant and predators are absent. These environments thus provide salamander larvae with a habitat with the lowest predation risk (Uiblein et al., 1992).

Larvae reared with dragonflies moved less than control larvae. Recent studies have proposed that direct contact with a potential predator can be perceived as a threat by aquatic newts more than the simple presence of cues (Winandy \& Denoël, 2013b). In direct contact, salamander larvae might also experience a closer disturbance or perception of potential risk from the dragonfly, increasing their caution and decreasing their movement. The treatment involving no direct contact with the 
predator was thus performed to test for the occurrence of habituation or different levels of threat perception, as have been observed in other study systems (Winandy \& Denoël, 2013a). Nevertheless, we did not detect any difference between conditions involving or not involving direct contacts, indicating that dragonfly larvae were perceived as a risk, even when they were not in direct contact with the salamanders in our study system. This result may be related to the fact that the duration of exposure was not the same, as in the indirect condition, salamanders were continuously exposed to the risk of predation, while in the direct condition, the risk of predation was very short in order to prevent the consumption of test larvae. Further tests should therefore focus on possible habituation effects. However, it is interesting to note that two very short direct expositions per week to predators lead to the same effect that permanent indirect exposition, underlying the strong impact of direct contact.

The behavioural responses of cave and stream larvae differed considerably, as cave larvae showed the strongest reduction in activity in the presence of predators during rearing, and in presence of predator cues during tests. Stream larvae did not move less in the presence of predator cues, indicating that individuals from the more risky environment assume the most risky behaviour (Urban, 2007). These result may be explained by the Ferrari et al.'s (2009) risk allocation hypothesis: in low risk habitats, when predators are absent or rare, prey can satisfy their trophic supply during relative long safe periods and thus respond strongly at the short and occasional predators' presence. In contrast, if conditions are highly risky with abundant predators, prey need to be active and forage even though predator cues occur. Streams are more risky also for other parameters, such as desiccation before metamorphosis, whereas underground sources in our study area have a permanent hydroperiod (Manenti, 2014). In ephemeral streams, with the constant presence of predators, a cautious behavioural strategy might cause an excessively long larval phase, also involving a higher risk of stream desiccation before metamorphosis. Conversely, the cost of reduced activity might be lower in cave pools, where the occurrence of predators is only occasional and delayed metamorphosis does not necessarily increase mortality. The relative fitness of individuals with risky and prudent antipredator strategies might thus be context-dependent and be strongly influenced by the interaction between predator presence, predator typology and the abiotic features of the breeding sites. Moreover, population divergence in growth rate may also exist, thereby influencing the effectiveness of different antipredator strategies (Laurila et al., 2006).

The predation risk differed considerably between epigean and hypogean sites: caves were devoid of potential predators, whereas epigeous streams were often inhabited by dragonfly larvae. Dragonflies are efficient predators of amphibian larvae and can have a strong impact on the density of salamanders (Manenti et al., 2013b), with a relevant impact on population dynamics (Drake et al., 2014; Kishida et al., 2009). Conversely, caves lack interspecific predators, but the limited food resources of underground habitats delay larval development (Limongi et al., 2015). When selecting breeding sites, females thus face two potential strategies: a risky strategy in streams and a more prudent strategy in caves.

In the populations studied here, it is not known whether differences between cave and stream larvae are mostly determined by local adaptations, or whether non-genetic maternal effects play a role. Responses to predators generally depend on two mechanisms: exposure to different background levels of risk (Ferrari, 2014) and associative learning that allows prey to associate novel stimuli to danger (Mathis et al., 2008). Selection is predicted to favour early learning in development, and it has been shown that even embryonic conditioning affects larval antipredator responses in amphibians (Ferrari et al., 2015; Mathis et al., 2008). Fire salamanders are ovoviviparous, thus embryonic exposure is impossible. Nevertheless, although taken shortly after birth, we cannot exclude an influence of the very first post-hatching experience to which larvae were exposed in their original habitat. In any case, the strong response to the predator in individuals from cave populations suggests some contact between these predators and the fire salamanders breeding in caves. Because local adaptations often reduce the ability to recognise or respond to predators that the populations have not encountered during recent evolutionary history, it is likely that gene flow occurs between salamanders 
that breed in caves and in streams. Indeed, individuals that metamorphose in caves usually leave them and can then potentially breed with individuals originating from the surrounding epigean streams or springs, even though assortative mating might limit the gene flow between stream- and cave-breeding females, thus allowing the persistence of local adaptations (Caspers et al., 2009). Further population genetics studies are necessary to determine the potential differences between cave and epigean populations.

The heterogeneity of predation pressure across environments can determine strong intraspecific variation of behaviour. Such variability can be a key factor favouring the colonisation of novel habitats, and can also arise between nearby populations living in contrasting habitats. However, studies on antipredatory response often focus on one single population. As antipredatory response may show contrasting patterns among habitats, we stress the importance of including among-population variation in this kind of studies.

\section{Acknowledgements}

We are grateful to two anonymous reviewers and the editor, S. Dalesman, for their constructive comments on the manuscript, and to B. Barzaghi and L. Tagliaferro for help during field surveys. M.D. is a Senior Research Associate at Fonds de la Recherche Scientifique (F.R.S.-FNRS). This research was funded by a Fonds Spéciaux pour la Recherche grant C15/63 (University of Liège). G.F.F. is a member of the Laboratoire d'Ecologie alpine (LECA), which is part of Labex OSUG@2020 (Investissements d'avenir - ANR10 LABX56) and M.D. is member of the Applied and Fundamental Fish Research Center (AFFISH).

\section{References}

Amo, L., Lopez, P., \& Martin, J. (2003). Risk level and thermal costs affect the choice of escape strategy and refuge use in the wall lizard, Podarcis muralis. Copeia, 2003, 899-905.

Barnett, H. K., \& Richardson, J. S. (2002). Predation risk and competition effects on the life-history characteristics of larval Oregon spotted frog and larval red-legged frog. Oecologia, 132, 436444.

Bates, D., Maechler, M., Bolker, B. M., \& Walker, S. 2014. lme4: linear mixed-effects models using S4 classes. R package version 1.0-6. www.r-project.org.

Blanchet, S., Bernatchez, L., \& Dodson, J. J. (2007). Behavioural and growth responses of a territorial fish (Atlantic salmon, Salmo salar, L.) to multiple predatory cues. Ethology, 113, 1061-1072.

Blaustein, L. (1997). Non-consumptive effects of larval Salamandra on crustacean prey: Can eggs detect predators? Oecologia, 110, 212-217.

Breheney, P., \& Burchett, W. 2015. visreg: Visualization of regression models. R package version 2.2-0. http://CRAN.R-project.org/package=visreg.

Carlson, B. E., \& Langkilde, T. (2014). Predation risk in tadpole populations shapes behavioural responses of prey but not strength of trait-mediated indirect interactions. Oikos, 123, 1519-1527.

Caspers, B. A., Junge, C., Weitere, M., \& Steinfartz, S. (2009). Habitat adaptation rather than genetic distance correlates with female preference in fire salamanders (Salamandra salamandra). Frontiers in Zoology, 6, 13.

Caspers, B. A., Steinfartz, S., \& Krause, E. T. (2015). Larval deposition behaviour and maternal investment of females reflect differential habitat adaptation in a genetically diverging salamander population. Behavioral Ecology and Sociobiology, 69, 407-413.

Chao, A., \& Chang, S. H. (1999). An estimating function approach to the inference of catch-effort models. Environmental and Ecological Statistics, 6, 313-334.

Chivers, D. P., Wildy, E. L., Kiesecker, J. M., \& Blaustein, A. R. (2001). Avoidance response of 
juvenile pacific treefrogs to chemical cues of introduced predatory bullfrogs. Journal of Chemical Ecology, 27, 1667-1676.

Davenport, J. M., \& Chalcraft, D. R. (2013). Nonconsumptive effects in a multiple predator system reduce the foraging efficiency of a keystone predator. Ecology and Evolution, 3, 3063-3072.

Delcourt, J., Denoël, M., Ylieff, M., \& Poncin, P. (2013). Video multitracking of fish behaviour: a review and future perspectives. Fish and Fisheries, 14, 186-204

Denoël, M., Bichot, M., Ficetola, G. F., Delcourt, J., Ylieff, M., Kestemont, P., \& Poncin, P. (2010). Cumulative effects of road de-icing salt on amphibian behavior. Aquatic Toxicology, 99, 275280.

Dodd, C. K. J. (2010). Amphibian Ecology and Conservation. Oxford: Oxford University Press.

Drake, D. L., Anderson, T. L., Smith, L. M., Lohraff, K. M., \& Semlitsch, R. D. (2014). Predation of eggs and recently hatched larvae of endemic ringed salamanders (Ambystoma annulatum) by native and introduced aquatic predators. Herpetologica, 70, 378-387.

Epp, J., \& Gabor, C. R. (2008). Innate and learned predator recognition mediated by chemical signals in Eurycea nana. Ethology, 114, 607-615.

Ferrari, M. C. O. (2014). Short-term environmental variation in predation risk leads to differential performance in predation-related cognitive function. Animal Behaviour, 95, 9-14.

Ferrari, M. C. O., Crane, A. L., Brown, G. E., \& Chivers, D. P. (2015). Getting ready for invasions: can background level of risk predict the ability of naïve prey to survive invasive predators? Scientific Reports, 5, 8309.

Ferrari, M. C. O., Sih, A., \& Chivers, D. P. (2009). The paradox of risk allocation: a review and prospectus. Animal Behaviour, 78, 579-585.

Godsall, B., Coulson, T., \& Malo, A. F. (2014). From physiology to space use: energy reserves and androgenization explain home-range size variation in a woodland rodent. Journal of Animal Ecology, 83, 126-135.

Hernandez, S. A., \& Peckarsky, B. L. (2014). Do stream mayflies exhibit trade-offs between food acquisition and predator avoidance behaviors? Freshwater Science, 33, 124-133.

Jusczcyk, W., \& Zakrzewski, M. (1981). External morphology of larval stages of the spotted salamander Salamandra salamandra (L.). Acta Biologica Cracoviensa, 23, 127-135.

Kishida, O., Trussell, G. C., Nishimura, K., \& Ohgushi, T. (2009). Inducible defenses in prey intensify predator cannibalism. Ecology, 90, 3150-3158.

Kishida, O., Trussell, G. C., Ohno, A., Kuwano, S., Ikawa, T., \& Nishimura, K. (2011). Predation risk suppresses the positive feedback between size structure and cannibalism. Journal of Animal Ecology, 80, 1278-1287.

Krause, E. T., \& Caspers, B. A. (2015). The influence of a water current on the larval deposition pattern of females of a diverging fire salamander population (Salamandra salamandra). Salamandra, 51, 156-160.

Kuznetsova, A., Brockhoff, B., \& Christensen, H. B. 2015. lmerTest: Tests in Linear Mixed Effects Models. R package version 2.0-29.: www.r-project.org.

Laurila, A., Pakkasmaa, S., \& Merilä, J. (2006). Population divergence in growth rate and antipredator defences in Rana arvalis. Oecologia, 147, 585-595.

Lima, S. L. (1998). Stress and decision making under the risk of predation: recent developments from behavioral, reproductive, and ecological perspectives. Advances in the Study of Behavior, 27, 215-290.

Lima, S. L., \& Bednekoff, P. A. (1999). Temporal variation in danger drives antipredator behavior: The predation risk allocation hypothesis. American Naturalist, 153, 649-659.

Limongi, L., Ficetola, G. F., Romeo, G., \& Manenti, R. (2015). Environmental factors determining growth of salamander larvae: a field study. Current Zoology, 61, 421-427.

Manenti, R. (2014). Role of cave features for aquatic troglobiont fauna occurrence: effects on "accidentals" and troglomorphic organisms distribution. Acta Zoologica Academiae Scientiarum Hungaricae, 60, 257-270. 
Manenti, R., Denoël, M., \& Ficetola, G. F. (2013a). Foraging plasticity favours adaptation to new habitats in fire salamanders. Animal Behaviour, 86, 375-382.

Manenti, R., \& Ficetola, G. F. (2013). Salamanders breeding in subterranean habitats: local adaptations or behavioural plasticity? Journal of Zoology, 289, 182 - 188.

Manenti, R., Ficetola, G. F., Bianchi, B., \& De Bernardi, F. (2009). Habitat features and distribution of Salamandra salamandra in underground springs. Acta Herpetologica, 4, 143-151.

Manenti, R., Ficetola, G. F., Marieni, A., \& De Bernardi, F. (2011). Caves as breeding sites for Salamandra salamandra: habitat selection, larval development and conservation issues. NorthWestern Journal of Zoology, 7, 304-309.

Manenti, R., Pennati, R., \& Ficetola, G. F. (2015). Role of density and resource competition in determining aggressive behaviour in salamanders. Journal of Zoology, 296, 270-277.

Manenti, R., Siesa, M. E., \& Ficetola, G. F. (2013b). Odonata occurrence in caves: active or accidentals? A new case study. Journal of Cave and Karst Studies, 75, 205-209.

Mathis, A., Ferrari, M. C. O., Windel, N., Messier, F., \& Chivers, D. P. (2008). Learning by embryos and the ghost of predation future. Proceedings of the Royal Society B-Biological Sciences, 275, 2603-2607.

Nakagawa, S., \& Schielzeth, H. (2013). A general and simple method for obtaining R2 from generalized linear mixed-effects models. Methods in Ecology and Evolution, 4, 133-142.

Preisser, E. L., \& Bolnick, D. I. (2008). When predators don't eat their prey: Nonconsumptive predator effects on prey dynamics. Ecology, 89, 2414-2415.

Satterthwaite, F. E. (1946). An approximate distribution of estimates of variance components. Biometrics, 2, 110-114.

Stav, G., Blaustein, L., \& Margalit, Y. (2000). Influence of nymphal Anax imperator (Odonata: Aeshnidae) on oviposition by the mosquito Culiseta longiareolata (Diptera: Culicidae) and community structure in temporary pools. Journal of Vector Ecology, 25, 190-202.

Storfer, A., \& Sih, A. (1998). Gene flow and ineffective antipredator behavior in a stream-breeding salamander. Evolution, 52, 558-565.

Uiblein, F., Durand, J. P., Juberthie, C., \& Parzefall, J. (1992). Predation in caves - the effects of prey immobility and darkness on the foraging behavior of two salamanders, Euproctus asper and Proteus anguinus. Behavioural Processes, 28, 33-40.

Uiblein, F., Engelke, S., \& Parzefall, J. (1995). Trade-off between visual detectability and nutrient content in the patch choice of the Pyrenean salamander Euproctus asper. Ethology, 101, 39-45.

Urban, M. C. (2007). Risky prey behavior evolves in risky habitats. Proceedings of the National Academy of Sciences of the United States of America, 104, 14377-14382.

Winandy, L., Darnet, E., \& Denoël, M. (2015). Amphibians forgo aquatic life in response to alien fish introduction. Animal Behaviour, 109, 209-216.

Winandy, L., \& Denoël, M. (2013a). Cues from introduced fish alter shelter use and feeding behaviour in adult alpine newts. Ethology, 119, 121-129.

Winandy, L., \& Denoël, M. (2013b). Introduced goldfish affect amphibians through inhibition of sexual behaviour in risky habitats: an experimental approach. Plos One, 8, e82736.

Winandy, L., \& Denoël, M. (2015). Expression of sexual ornaments in a polymorphic species: phenotypic variation in response to environmental risk. Journal of Evolutionary Biology, 28, 1049-1056.

Yorzinski, J. L., Chisholm, S., Byerley, S. D., Coy, J. R., Aziz, A., Wolf, J. A., \& Gnerlich, A. C. (2015). Artificial light pollution increases nocturnal vigilance in peahens. Peerj, 3, e1174. 
Article history:

Received 23 February 2016

Initial acceptance 6 April 2016

Final acceptance 23 May 2016

Available online 30 June 2016

MS. number: 16-00151R

Supplementary Figure S1. Location of study sites of fire salamander larvae (Italy). Grey symbols: sites used only for the field surveys; black symbols: sites from which we collected the larvae for the behavioural tests. Triangles and squares represent stream and cave sites, respectively. 